\section{References}

BENNETT. D. (1991) The drive towards the community. In 150 Years of British Psychiatry 1841-1991 (eds G. Berrios \& H. Freeman), pp. 321-332. London: Gaskell.

DePartment of HEALTH (1990) 'Caring for People'. The Care Programme Approach for People with a Mental Mlness Referred to the Specialist Psychiatric Services. Heywood: Department of Health.

GOURNAY, K. \& BROOKING. J. (1994) Community psychiatric nurse in primary health care. British Journal of Psychiatry. 165, 231-238.

ISAACS. A. D. \& BEbBington, P. B. (1991) Strategles for the management of severe psychotic lllness in the community. International Review of Psychiatry. 3. 71-82.

KINGDON. D. (1994) Making care programming work. Aduances in Psychiatric Treatment, 1, 41-46.

MARSHALL. M. (1996) Case management: a dubious practice. British Medical Joumal, 312, 523-524.

MELZER, D., HALE. A., MALK. S., et al (1991) Community care for patients with schizophrenia one year after discharge. British Medical Journal, 303, 1023-1026.

MUNEN, M.. MARKS, I.. CONNOLLY, J., et al (1992) Home based care and standard hospital care for patients with severe mental illness: a randomised controlled trial. British Medical Journal, 304, 749-754.

ONYETT. S. (1992) Case Management in Mental Health. London: Chapman and Hall.
SANtos. A. B., HengGeler. S. W.. Burns, B. J.. et al (1995) Research on field-based services: models for reform in the delivery of mental health care to populations with complex clinical problems. American Journal of Psychiatry, 162. 1111-1123.

Salokangas, R., Pala-OJa. T.. OJanen, M.. et al (1991) Needs for community care among psychotic outpatients. Acta Psychiatrica Scandinavica, 84, 191-196.

SaYCE, L., Craig, T. \& Boardman, A. (1991) The development of community mental health centres in the UK. Social Psychiatry and Psychiatric Epidemiology. 26. 14-20.

*Sean Feeney, Consultant Psychiatrist, North Kent Healthcare NHS Trust, and Honorary Senior Lecturer (UMDS) Swale Day Unit, Sittingbourne Memorial Hospital, Bell Lane. Sittingbourne, Kent ME1O 4DT; Steve Onyett, Head of Clinical Psychology Services/Senior Research Fellow, South Kent Community Healthcare NHS Trust, Folkestone, Kent; and Kevin Lindsay, Manager, Adult Mental Health Services, Invicta Community Care, Priority House, Maidstone, Kent

*Correspondence

\title{
Writing letters to patients
}

\author{
Phil Thomas
}

\begin{abstract}
Recent changes in the law and mental health pollcy have forced psychiatrists and other mental health professtonals to review the traditional cloak of secrecy that surrounds record keeping and letter writing. This paper establishes what proportion of patients attending a poychiatric out-patient clinic are interested in recelving letters from their psychiatrist. Those who are interested fend to be better educated, whereas those who are not interested are much more llkely to have an ICD-10 diagnosis of schizophrenia. Overall, there appear to be high levels of satisfaction with the nature of the letters recelved. The significance of these findings is cliscussed in relation to the difficulty of engaging people with the most severe and enduring forms of mental health problems as active participants in the process of care.
\end{abstract}

A recent Government paper (Department of Health. 1996) emphasises the importance of patient involvement in decision-making pro- cesses about treatment. Everyone agrees that psychiatric patients should be given the information necessary to understand and participate in their treatment, but there is no consensus as to the best way of achieving this. A Court of Appeal ruling in 1994 made it clear that while patients have a prima facie right of access to their clinical notes under the 1991 Access to Health Records Act, this may be denied under certain circumstances (Brahams, 1994). The 1991 Act triggered a flurry of papers examining the ethics of patient access (McLaren, 1991; Weil, 1993) or its practicalities (Parrott et al, 1988; Asch et al, 1991; Bernadt et al, 1991). This signifies a move away from the tradition of medical paternalism to a more person-centred approach to health care. However, the discussion about access to medical records, and the related issue of patient involvement in decision-making processes about treatment, is dominated by an important assumption: 
that all patients want such access and involvement. This too is paternalistic, because it assumes that the doctor knows best. It disregards the possibility that there may be patients who do not wish to have access to their records, or who may not wish to be engaged in decisionmaking processes about their care. The purpose of this paper is two-fold: first, to find out what proportion of patients attending a psychiatric out-patient clinic want to receive letters from their consultant, and second, to find out what people think of the letters they receive.

\section{The study}

This study is the first of a series examining the processes necessary to involve psychiatric outpatients more actively in their own care. The first stage identifies patients who were interested in receiving letters from their consultant. The second stage (currently under way) consists of a content analysis of letters written to these patients and to their general practitioners (GPs). There is little point writing to patients if they cannot understand letters which are full of medical terminology.

Consecutive attenders at a psychiatric outpatient clinic from June to November 1995 $(n=98)$ were eligible for the first part. Patients suffering from organic brain syndromes $(n=11)$ were excluded, as were those discharged from out-patient care $(n=8)$ during the course of the study, leaving 79 who were eligible for inclusion. The majority had been attending psychiatric clinics for many years. At the end of each consultation the purpose of letter writing was explained. Patients were told that the consultant usually wrote to the GP to report on progress, but if the patient preferred, the consultant would write to the patient instead with a copy to the GP. The purpose of this was to provide a record for the patient's future reference, and to ensure the accuracy of the material obtained during the course of interviews. Patients were encouraged to write back correcting any inaccuracies, or with any other comment. All patients were asked which they would prefer (a letter from the consultant or for the consultant to continue the practice of writing to the GP).

Eighteen months later, demographic and clinical details were obtained from patients' case notes. These included age at the time of inclusion in the study, gender, marital status, educational attainment, social class (based on Registrar General's classification), duration of illness, subsequent duration of clinic attendance and clinic status 18 months later (case still active, discharged or self-discharged). Each patient's ICD-10 (World Health Organization, 1992) diagnosis was coded from the case notes, although a simpler system of classification based on these codes is used here. The categories are as follows: dementia or organic brain syndrome; schizophrenia and paranoid states; affective disorders; depression; anxiety disorders; interpersonal problems; abusive relationship problems (these include people whose problems are primarily attributable to the effects of past or present abuse in relationships); other, including alcohol misuse.

All patients who received letters were sent a short questionnaire seeking their views about the letters. The form and content of the questionnaire was similar to that used by Asch et al (1991). Subjects were asked how helpful they had found the letters, whether they were easy to understand and how accurate and relevant they found them.

\section{Findings}

Characteristics of those who requested, and those who did not request letters

Of the 79 patients who were asked whether they would like to receive letters, $48(61 \%)$ said that they would. This includes two people who said no initially, and later changed their minds. No patient who said yes initially subsequently asked not to receive letters. There were no differences in mean age (yes/no; 51.7 and 51.8 years, respectively) or gender distributions of the two groups (65\% of women and $55 \%$ men said yes), although there was a non-significant tendency for those who said no to have been ill for a longer period of time (15.3 years compared with 12.9 years). Those who said yes tended to be better educated; $40 \%$ had ' $A$ '-levels or degrees, compared with only $8 \%$ of those who said no $(P<0.01)$. There were no significant differences in the social class distribution of the two groups and marital status.

People with a diagnosis of schizophrenia were much less likely to request a letter (25\%) compared with all other diagnostic groups $(70 \%, P<0.01)$. They were also more likely to come from social class 4 or $5(68 \%)$ compared with the other groups $(41 \% ; 0.1>P>0.05)$ but there were no statistically significant differences in educational attainment between the two main diagnostic groups. In the sample as a whole, people from social class 1 to 3 had a significantly higher educational attainment. Forty-eight per cent had ' $A$ ' levels or a degree, compared with $4 \%$ for people from social classes 4 and $5(P<0.001)$. Educational attainment also appeared to be the major determinant of letter choice in the nonschizophrenic group, $39 \%$ of whom requested a letter had ' $A$ ' levels or a degree, compared with $7 \%$ of those who did not $(P<0.05)$. 


\section{Patients' views of letters}

At 18 months' follow-up, two of the 48 people who asked for letters had died (one from myocardial infarction, the other of diabetic ketoacidosis). Responses were received from 32 of the remaining 46 , a response rate of $70 \%$. The results are presented in Table 1, where the fivepoint scale is collapsed into three (dissatisfied, neutral and satisfied). The responses indicated a high level of satisfaction with the letters received. The majority of patients found letters helpful $(91 \%)$, easy to understand $(87 \%)$, factually accurate $(90 \%)$ and relevant to their problems as they saw them (94\%). Few patients found their letters difficult to understand $(3 \%)$, or were upset by their letters $(10 \%)$. Many patients $(67 \%)$ showed their letters to others, including spouse or partner $148 \%$ of those who shared the information), other relative $(20 \%)$ and friend or community mental health team member (12 and $16 \%$ each).

Approximately half the respondents made additional written comments about their letters. The most frequent of these concerned the value of letters as an aide-mémoire (six subjects), and the reassuring and supportive function of letters (five). Three people commented that they found it helpful to look back at the letters over time to see how much they had improved, and three commented on the person-centred nature of the letters. This can be seen most clearly in the following extract from a comment made by one respondent

"The tone of the letters i.e. not patronising but one sensible, intelligent person writing to another, helped the battered self-image and to feel that this was a partnership tackling the problems."

Others commented that letters helped them to see their problems more clearly. There were few problems to emerge from these comments. One person was against copies of letters being sent to GPs because "they don't understand mental health, nor care". Another person commented that letters did not interest her, and that she had destroyed them after reading them. Another noted that the letters made her feel more anxious, because she did not want her partner to discover what they contained.

\section{Comment}

Two factors stand out in terms of whether or not patients are interested in receiving letters: diagnosis and educational attainment. People diagnosed with schizophrenia were much less likely to express an interest in receiving letters. as were people who had lower levels of educational attainment. These factors appear to operate independently. There were no significant differences between diagnostic groups for educational attainment, and people who had poor educational attainment were much more likely not to be interested in receiving letters in the non-schizophrenic group. Social class appeared to have little effect on letter choice.

This study has implications for person-centred approaches that seek to engage patients as equals in the process of care. We make a serious mistake if we assume that being more open with our patients, such as sending them copies of letters, means that they become empowered as active partners in care. This may be so for bettereducated subjects, and those who are not suffering from the most severe and enduring mental health problems, but otherwise it appears not to be the case. People suffering from schizophrenia face enormous social adversity. yet psychiatrists, in trying to help them, are increasingly reliant on conceptual frameworks that place greater emphasis on neuroscientific explanations of schizophrenia and the treatment of the condition with medication (Thomas et al, 1996; Thomas, 1997). This study highlights the difficulties of trying to resolve a paradox in working with individual patients. The very group for whom engagement in dialogue about the nature of their problems (such as through the process of writing letters) seems essential, appears least likely to want to engage in such dialogue. This study is unable to throw light on the reasons for this, but there are several possibilities. It may relate to the clinical and cognitive features of this group of patients, many of whom had prominent negative symptoms such

Table 1. Responses to questionnaire about letters $(n=30)$

\begin{tabular}{lccl}
\hline & Dissatisfied & Neutral & Satisfied \\
\hline Letters helpful & $4 \%$ & $6 \%$ & $90 \%$ \\
Easy to understand & $0 \%$ & $13 \%$ & $87 \%$ \\
Accurate & $3 \%$ & $7 \%$ & $90 \%$ \\
Reflect problem & $0 \%$ & $4 \%$ & $96 \%$ \\
Relevance & $0 \%$ & $6 \%$ & $94 \%$ \\
Aid understanding & $3 \%$ & $7 \%$ & $90 \%$ \\
Cause upset & $10 \%$ & $10 \%$ & $80 \%$ \\
\hline
\end{tabular}


as poverty of speech, restricted affect and social withdrawal. Alternatively, this group's experience of mental health services was characterised by long periods of hospitalisation, often under section. Williams $(1994 a)$ has shown that the past experience of this group of users may contribute to higher levels of dissatisfaction. In addition, the adoption of a passive and detached stance in relation to one's problems may be an important way of coping with painful and difficult parts of one's own experience. Support for this view is to be found in the work of Corin $\&$ Lauzon (1992) who, using a phenomenological framework, have explicated the different levels of meaning of negative symptoms. Withdrawal and disengagement from social relationships can play an important part in subjects' attempts to make sense out of their experiences. The results of the present study indicate that this is an area worthy of more detailed study using qualitative techniques in this group of subjects.

The response rate to the questionnaire survey was satisfactory at $70 \%$, although a word of caution is necessary in interpreting the results of the survey. Williams $(1994 b)$ has described problems with the validity of quantitative surveys such as this. It is difficult to know whether expressions of satisfaction reflect genuine satisfaction with the item being considered, or whether subjects' responses reflect confidence in the staff ("the service was appalling but I don't like to criticise, after all they're doing their best", Williams, 1994b, p. 514). With this caveat in mind, the results of the survey do suggest. however, that people who ask for letters find them helpful and useful. Letters were easy to understand, accurate and relevant. This is important because letters were consciously written so as to be understandable by the patient. Shah \& Pullen (1995) have commented on the importance of keeping letters to GPs free of jargon. This is even more important for letters written to patients. There is little point in writing to patients if the recipient cannot understand the letter. A real effort had to be made to avoid technical expressions, and to make the content of letters relevant to the patient's problems as described in the clinic. A more detailed study is in progress using a content analysis of letters written to GPs and patients, to establish whether the two types of letters differ in regard to nature of information contained.

\section{References}

Asch, R., Price. J. S. \& Hawks, G. (1991) Psychiatric outpatients' reactions to summary letters of their consultations. British Journal of Medical Psychology. 64. 3-9.

Bernadt. M.. Gunning. L. \& Questedt. M. (1991) Patients access to their own psychiatric records. British Medical Journal, 303, 967.

BRAHAMS, D. (1994) Right of access to medical records. Lancet, 344. 743.

Corin. E. \& LAUZON. G. (1992) Positive withdrawal and the quest for meaning: the reconstruction of experience among schizophrenics. Psychiatry. 55. 266-278.

DEPARTMENT OF HEALTH (1996) The National Health Service: A Service with Ambitions. London: HMSO.

MCLAREN. P. (1991) The right to know: Patients' records should be understandable by patients, too. British Medical Journal, 303. 937-938.

PARROTt, J., Strathede, G. \& BRown, P. (1988) Patient access to psychiatric records: the patients' view. Journa of the Royal Society of Medicine, 81, 520-522.

SHAH. P. J. \& PULLEN, I. (1995) The impact of a hospital audit on psychiatrists' letters to general practitioners. Psychiatric Bulletin. 19. 544-547.

THOMAS. P. (1997) The Dialectics of Schizophrenia. London: Free Association Books.

-. Romme, M. \& Hemmeunik. J. (1996) Psychiatry and the politics of the underclass. British Journal of Psychiatry. 169. 401-404.

WEIL. F. (1993) The right of the mental patient to be medically informed. Medicine and Law, 12, 681-686.

WILliams, B. (1994a) Users' views of community mental health services. In Community Care: Evaluating the Provision of Mental Health Care (eds C. Crosby \& M. M. Barry). Aldershot: Avebury.

- (1994b) Patient satisfaction: a valid concept? Social Science and Medicine, 38. 509-516.

WORLD HEALTH ORGanization (1992) The Tenth Revision of the International Classification of Diseases and Related Health Problems (ICD-10). Geneva: WHO.

Phil Thomas, Senior Research Fellow and Consultant Psychiatrist, Department of Social and Economic Studies. University of Bradford. Richmond Building. Richmond Street, Bradford BD7 1DP 